heart. It is recorded that he was feared as an examiner, because of his brusque manners, but that he was, in truth, less severe than many of his colleagues. His firmness in pursuing what he believed to be for the public good, as well as his disregard for his own private wrongs, has been mentioned by all his contemporaries.

There are many portraits of him ; the best known, that in the Secretary's room at the Royal College of Surgeons (reproduced also in Pettigrew's Medical Portrait Gallery), is not the most pleasing.

The bust by Chantrey, in the Gallery, gives the impression of a much finer man, with a large outlook and wide sympathies. The bust in the "Guthrie" Ward of the R.W.O.H. is not a successful work of art.

A very life-like little sketch (reproduced here) is to be found in the Lancet for 1850 .

I have to thank Mr. D'Arcy Power and Professor Keith for their kind help in the collection of material on which this short memoir is based.

\title{
COMMUNICATIONS
}

\section{ON MAXIMAL INSTILLATION OF COCAIN AND OF ESERIN IN CATARACT EXTRACTION}

\author{
BY \\ H. Herbert, Lieut.-Colonel, I.M.S., \\ KARACHI, INDIA.
}

OPERATING for cataract in Sind, Northern India, during the past two years, local conditions have been largely responsible for a number of departures from the accepted routine procedure. Two of these changes are well worth consideration as valuable measures for at least occasional adoption elsewhere.

Prolonged instillation-period of cocain and adrenalin. Sindhis as a whole strike a lower average in self-control during operation than any body of patients which I have yet met. They are timid, suspicious, and bear pain badly. Consequently operations with only the usual preparation of the patient are too frequently nervewracking ordeals for the surgeon, and are unfair to the patient. One is forced to operate as frequently as possible under the full, or nearly full, influence of cocain. The stage reached in anaesthesia of the iris may be gauged fairly well by the degree of dilatation of the pupil attained under the combined instillation of adrenalin and cocain. As a general rule the dilatation must be rather wide if the patient is to be guaranteed free from pain on pulling or rubbing the 
iris. In our busy and imperfectly organized hospital practice, however, we have often begun operating upon eyes somewhat imperfectly anaesthetized, while, on the other hand, the later patients of a batch have occasionally been kept waiting for their turn some considerable time after they were quite ready for operation. So that we have had a fair experience both of over-use (? abuse) and of insufficient use of cocain.

The strong conjunctival reaction produced by our maximal perchloride irrigation delays the absorption of the adrenalin and cocain instilled, so that as much as thirty-five minutes has been at times occupied in obtaining complete anaesthesia. Adrenalin solution 1 in 1,000, is used once immediately after the perchloride washing, and a second time later if the eye remains injected. Four per cent. cocain drops are used every two, three, or four minutes, according to circumstances.

Even in cases where the cocain instillation has been prolonged beyond the desired stage, as above, trouble from drying of the cornea seems to be readily avoided by keeping the eyes closed between the instillations, and by dropping sterile water on the cornea after insertion of the speculum, and continuing it as appears necessary afterwards during the operation. With the lids closed, and with any excess of fluid at once mopped up from the lid margins after each instillation, apparently little or no fluid passes down into the nose to give rise to general symptoms.

Particularly in cases in which adrenalin has been used more than once, and in which the cocain instillation has been unusually prolonged, the palpebral aperture not infrequently remains imperfectly closed afterwards. On gentle closure of the lids, as in sleep, the aperture may remain 2 or $3 \mathrm{~mm}$. wide. And though the upper lid can be readily pushed into position, and retained there by the application of a cotton-wool pad without pressure, one would prefer natural closure, at least in cases in which a lower section has to be made. (A large proportion of lower sections are made in Karachi, as we have found it best in many instances to allow the patient to look where he pleases during the operation. But our lower sections are always more or less sub-conjunctival, the conjunctival flap being left undivided at the lower fornix.)

In a case narrated below, this imperfect closure of the lids apparently interfered with the local penetration of eserin drops used after operation.

Further observation is needed to dispose of the question whether other troubles or dangers may possibly arise from over-use of adrenalin and cocain. As seen from recent accounts, some Indian surgeons in large practice are now instilling these drops for periods up to one hour (!) before operating. Their experience should be valuable in this respect. The only two cases in my own practice 
with any possible bearing on the point are the following: 1. Several months ago an expulsive haemorrhage occurred three or four hours after operation. 2. There is a patient now in hospital who presumably had a smaller fundus haemorrhage six hours after operation. Pain was experienced then after coughing, and next day the wound was found pressed open by an extensive prolapse of vitreous (hyaloid unruptured) and of iris.

These are the only cases of expulsive or partly expulsive haemorrhage which have occurred recently in the Karachi hospital, and it seems possibly more than a coincidence that neither took place at the more usual time-during operation. Vascular dilatation in the reaction period after our operations may be often considerable, and in both these cases eserin had been used freely after operation, possibly increasing the vascular reaction. But even if experience should eventually show an increased tendency to destructive haemorrhage after operation when prolonged cocain instillation has been practised, this may be balanced by diminished frequency of the accident during operation, when the risk of it is ordinarily greatest. The unusual degree of constriction of the vessels at this time under full cocainization may have this effect. And lowering of tension before operation by the adrenalin and cocain may also lessen the risk of haemorrhage, which, when it occurs, ordinarily accompanies the sudden loss of tension due to the making of the incision. That such preliminary reduction of tension may be considerable is indicated by the frequency with which cupping or folding of the cornea is seen at the close of the operation in fully cocainized eyes. Rarely there is some slight tendency to folding of the sclera also.

Thus the possibility of ill-effects from our sometimes over-free use of cocain must be regarded as decidedly problematic. On the other hand, the advantages derived from the frequently attained complete anaesthesia have been very convincing. Undoubtedly we must have been spared a number of accidents and complications attributable to "squeezing" of the orbicularis during operation. To emphasize this point there has been one complete loss of vision in an imperfectly anaesthetized eye, from large loss of vitreous due to "squeezing"; and in another case a low-grade infection from fouling of the knife by the lid-margin, also due to contraction of the orbicularis. The reduction of ocular tension before operation must also tend somewhat to lessen the risk of vitreous escape during and after expulsion of the lens. And the dilatation of the pupil facilitates expulsion of the lens, thus enabling a large number of simple extractions to be performed with the minimum of stretching of the iris, and so reducing the risk of prolapse.

The effective use of eserin after simple extraction.-I have been endeavouring to settle the question whether, by the fullest use of eserin, anything approaching absolute security from risk of iris 
prolapse is obtainable after simple extraction. The value of a normal pupil is particularly great in the glare of India ; and in eyes rolled more or less upwards after an upper section has been made, much trouble may at times be avoided by dispensing with an iridectomy.

An order was issued to the assistants quite a year ago that no eye was to be bandaged up after simple extraction until the pupil was well contracted. But owing to constant changes in the personnel, the records have been very imperfectly kept, and there are no exact figures of the number of simple extractions performed. However, the enquiry has been far from barren encouraging a freer resort to the simple method, and opening up at least one side issue. A strict record is now being kept, from which figures may be found worthy of publication later.

The carrying out of the order, as issued, has not always been found practicable. Symptoms of slight poisoning have appeared in three patients lately, with the pupil still above or about the normal size. The patients have complained of pain in the epigastrium, with faintness and nausea, and have vomited. The eserin drops, 1 per cent., have generally been instilled at two wide intervals, between the successive operations on batches of patients. The better way, probably, is to instil five or six times at about oneminute intervals immediately after operation, and to add more, if found necessary, half an hour or so later. For in Bombay years ago we found that three or four instillations at one-minute intervals generally resulted in satisfactory miosis next day.

The influence in this connection of the adrenalin instilled before operation is not quite simple. In Bombay, the medicament was always at that time used once only, before the cocain instillations, and we were convinced that the contraction of the pupil produced (next day) wasmuch more constant and marked than in earlier days when no adrenalin was used. When adrenalin was not used there was so much conjunctival irritation from the preliminary maximal perchloride irrigation that the eserin drops instilled after operation could be seen largely to be washed away in tears. The adrenalin by preventing or limiting the secretion of tears, evidently assisted in the local absorption of the eserin, thus indirectly overcoming the mydriasis which, in combination with the cocain, it had produced. But in those days there was only the moderate enlargement of pupil produced by one instillation of adrenalin and four of cocain to be overcome. The symptoms of poisoning in the three instances mentioned came on after 8,9 , and " about 20 " (! !) instillations of eserin. They were quite transient in each case. In the first case a hypodermic injection of morphia gave quick relief. In the others nothing was administered.

The first case of poisoning, in which eserin was instilled about 
twenty times, was a little alarming. Besides presenting the most resistent pupil, it was exceptional in other ways. Adrenalin had been used three times before operation, and the separation of the lids after operation, on gentle closure, was the widest I have seen. The lids were quite $4 \mathrm{~mm}$. apart. The earlier eserin instillations were made simply by depressing the lower lid, and probably very little of the solution found its way under the practically motionless upper lid. Later, however, the assistant moved the upper lid at each instillation to assist diffusion, and then kept it in place with a moistened cotton-wool pad. The instillations were continued every 5-10 minutes for $2 \frac{1}{2}$ hours, until stopped by the general symptoms already mentioned. The pupil was still above the normal size. It evidently contracted later, but too late to prevent an incarceration of the base of the iris in the wound, for next day a narrow slit-like pupil was found reaching to the upper margin of the cornea. In the two other cases of (slight) poisoning, also, the drops were stopped with the pupils perhaps slightly above the normal size, but the next day both pupils were quite small.

Our difficulties have been increased by local conditions. The state of the Indian conjunctiva has necessitated very free perchloride irrigation ( 2 to 3 minutes with 1 in 3,000 solution), and this, together with the feeble mental control of the patients, has necessitated a freer use of adrenalin and cocain than would ordinarily be required in Europe. Hence the time and trouble taken in overcoming a wider mydriasis than would commonly be encountered elsewhere.

Thus, according to present evidence, while one instillation of adrenalin, with a moderate use of cocain, has the curious effect, apparently, of assisting in the production of miosis later, a freer use of these drops may have the opposite effect, retarding the action of eserin, as one would expect.

To return to the main question of the attainment of practical security from risk of iris prolapse, it is encouraging that as yet the answer is not definitely negative. In the early days of the enquiry there were two definite prolapses, but they were in the only two eyes in which the pupil was left distorted and displaced at the close of the operation. There is no record of the number of eserin instillations used or of the state of the pupils afterwards. It is too much to expect that eserin should pull such pupils into place, and the enquiry is thus narrowed to uninjured irides, with round and more or less central pupils. There have been two incarcerations of the base of the iris in the wound. One has been already referred to above. It is not surprising that the imperfect action of eserin, described in this case, should have failed to keep the iris in position. But the continued instillation of 1 per cent. eserin solution four times each morning and evening not only prevented the incarceration from enlarging into a prolapse, but actually pulled the iris back 
somewhat, so that the patient was discharged with a pupil only moderately displaced and V. of $\frac{6}{6}$ partly with $+10 \mathrm{D}$. sph. $こ+3.5$ D. cyl. In the other case there was no excuse of imperfect action of eserin. Next day the pupil was found small, but elongated and somewhat displaced up. Eserin drops were continued only three times a day, for an insufficient period. As a result iris became visible at the surface of the globe a fortnight later, with a barely perceptible elevation at one point.

In conclusion, it is only fair to recall and to utilize one of the Sindhi's good points. He makes a more intelligent hospital patient than the average elsewhere in India. Thus he appreciates the best possible result, with the least possible risk, and to obtain this he does not object to a fairly prolonged after-treatment, including "needling" when necessary. Hence, in the new Karachi Eye Hospital, opened this year, the material is at hand wherewith to demonstrate to a sufficiently critical public the superiority of the more established methods over the intra-capsular extraction now so widely practised in Northern India. There are two essentials in any such attempt. (1) A fair number of supplementary needlings must be performed; and (2) the safety aftorded by maximal perchloride irrigation must be utilized always, both in the primary and in the secondary operation. Of great assistance also in this endeavour will be the extended practice of simple extraction, which seems possible if the promise shown above, by the judicious use of adrenalin, of cocain, and of eserin, is substantiated.

\title{
INJURY TO THE EYE FROM SPECTACLE GLASS
}

\author{
BY \\ D. V. Giri, D.O. (Oxon.), \\ EASTBOURNE.
}

Cases

CASE I.-On August 8, 1916, R- K- - aged 62 years, came to the hospital with the history that three days previously, while chopping wood, a piece flew up and hit his right glass, which broke and pierced the eye.

On examination, I found : R.E. ecchymosis just below the lower lid. Subconjunctival haemorrhage below the limbus corneae and between it and the internal canthus. Perforating wound of the cornea in the lower inner quadrant. Behind the perforation, where probably the iris is adherent, a small clot of blood in the anterior chamber, which is very shallow. Iris somewhat bulged forward. Pupil semi-dilated and inactive. $\mathrm{T}-$. The fundus, the details of which became visible only with the help of the strongly luminous 